I conclude that comparison of the rift locations shown in Figs. 1 and 2 shows that the $n=5$ degree convection pattern explains most closely the observations. This is especially interesting in the light of the harmonic analysis of topography by Prey and Vening Meinesz, the theoretical work of Vening Meinesz and Chandrasekhar and the continental drift arguments of Runcorn, all which show the strong possibility of a mantle convection pattern of the same degree.

${ }^{1}$ Tuzo Wilson, J., Nature, 197, 536 (1963).

2 Girdler, R. W., Nature, 194, 521 (1962).

3ening Meinesz, F. A., Kon. Ned. Akad. Weten., 55, 527 (1952).
4 Chandrasekhar, S., Phil. Mag., 44, 233, 1129 (1953).

5 Runcorn, S. K., Nature, 193, 311 (1962).

- Runcorn, S. K., Nature, 195, 1248 (1962).

Prey, A., Abh. Ges. der Wissenschaften Math. Phys. Klasse (Gottingen), 11, 1 (1922).

${ }^{8}$ Rothé, J. P., Proc. Roy. Soc., A, 222, 387 (1954).

${ }^{8}$ Rothé, J. P., Proc. Roy. Soc., A, 222, 387 (1954).

${ }^{10}$ Menard, H. W., Experientia, 16, 205 (1959).

${ }^{11}$ Ewing, M., and Heezen, B. C., Science, 181, 1677 (1960).

${ }^{12}$ Menard, H. W., Science, 132, 1737 (1960).

${ }^{13}$ Heezen, B. C., Tharpe, Marie, and Ewing, M., Geol. Soc. Amer. Spec. Pap., 65 (1959).

14 Girdler, R. W., Quart. J. Geol. Soc, Lond., 114, 79 (1958).

${ }^{16}$ Hess, H. H., Proc. Roy. Soc., A, 222, 341 (1954).

${ }^{16}$ Urey, H., The Planets (Oxford Univ. Press, 1952).

\title{
OBITUARIES
}

\section{Prof. E. C. Titchmarsh, F.R.S.}

By the death on January 18 of Prof. Edward Charles Titchmarsh, British mathematics has lost an analyst of internationally recognized eminence, who has contributed more than any other man to the continuation of the traditions of the British school of classical analysis established by Hardy and Littlewood.

Titchmarsh was born in Newbury, Berkshire, on June 1, 1899, and was the eldest son of Edward Harper Titchmarsh, a Congregational minister. $\mathrm{He}$ was educated at King Edward VII School, Sheffield, from 1908 until 1917; at first he was on the classical side, but moved to mathematics, and won an open mathematical scholarship at Balliol College, Oxford, in 1916. After one term at Balliol, he was away for two years as a lieutenant in the Royal Engineers (Signals). In 1919 he returned to Oxford and was much influenced by G. H. Hardy; his last year in Oxford was spent on research under Hardy's supervision.

In 1923 he was appointed as a lecturer at University College, London, and at the same time became a Fellow of Magdalen College, Oxford. In 1925 he married Kathleen Blomfield, by whom he had three daughters. In 1929 he became professor of pure mathematics at Liverpool and in 1931 Savilian professor of geometry at Oxford in succession to Hardy, a post which he held for the rest of his life together with a professorial fellowship of New College; in the same year he was elected a Fellow of the Royal Society.

Throughout his working life, Titchmarsh showed a single-minded devotion to classical analysis: he accepted his chair at Oxford on condition that he should not lecture on geometry. His earliest research work was devoted to problems concerning the expression of functions in series or integrals in terms of given functions, an interest which lasted throughout his life. His most important work at this time was on Fourier transforms, particularly the extension of Plancherel's theorem to the $L^{p}$ classes of functions, and soon after he made important contributions to the theory of conjugate functions. His contributions to this field, together with his work on general integral transforms, and on the applications of Fourier integrals to the solution of differential and integral equations, laid the basis of his Introduction to the Theory of Fourier Integrals (1937).

In the meantime, Titchmarsh's interests had extended to cover the theory of integral functions, and in particular of the zeta function. A series of his papers were devoted to the study of the properties of the zeta functions, particularly to the still unsolved problem of the location of its zeros. This work was brought together in a Cambridge Tract, The Zeta Function of Riemann, in 1930 and later treated more fully in The Theory of the Riemann Zeta-Function, published in 1951. His book on The Theory of Functions (1932) grew out of this interest in complex variable theory; like his book on Fourier integrals, it is internationally recognized as a leading text on both real and complex function theory and has been translated into several languages.

From 1939 onwards Titchmarsh devoted himself in the main to the theory of expansions of functions in eigenfunctions of differential equations, a subject which he treated in a large number of papers, including four published this year, and in Part 1 (1946) and Part 2 (1958) of his book on Eigenfunction Expansions associated with second order Differential Equations. This is a subject which is vital to quantum theory; before his work there was a considerable gap between the general theory and the methods used by physicists to solve particular problems. Titchmarsh's theory combines a general theory for second order differential equations with techniques useful for the study of the spectrum in particular cases. After working on ordinary differential equations he moved to partial differential equations. He interested himself in problems of importance in physics: his last published papers, for example, dealt with completeness problems for eigenfunctions of equations of relativistic quantum theory. He concentrated on those aspects of these problems with which he was supremely fitted to deal: he never commented on the physical aspect of the problems, an attitude typified by the dry humour of the preface of his book on Fourier integrals which states that though problems of physics are dealt with, the reader need not know that such things exist. This work has led to important developments by mathematicians in many countries.

Titchmarsh was of a retiring nature but had a capacity for dry humour in conversation and in his social duties. To his research students he was always approachable and guided many towards important contributions to mathematics. He took an active part in the administration of New College and of the London Mathematical Society in his term as president during 1945-47. During the Second World War he worked assiduously on the provision of books for prisoners of war. Gardening and cricket were among his other interests.

His distinction was recognized by the award of the de Morgan Medal of the London Mathematical Society in 1953, and of the Sylvester Medal of the Royal Society in 1955 .

$$
\text { J. L. B. Cooper }
$$

\section{Mr. James Macdonald, C.B.E.}

JAmes Macdonald, formerly deputy director-general of the Forestry Commission, died on April 28 at the age of sixty-four. He had been in failing health for the past year and retired on that account in January of this year.

Macdonald was educated at Blairgowrie High School, and then after a period of Army service went to the University of Edinburgh, where he graduated B.Sc. in forestry in 1923. He studied forest pathology under Dr. Malcolm Wilson for a further year, when he was appointed to the research staff of the Forestry Commission. 